\title{
Die geheim van die prediking: om na die stem van die teks te luister
}

\author{
J Cilliers
}

(Universiteit van Stellenbosch)

\section{ABSTRACT}

\section{The secret of preaching: listening to the voice of the Biblical text}

This paper concentrates on the function of the Biblical text in preaching, contending that there can in fact be no preaching in the true sense of the word if the text is not honoured both in its content and form. It argues that a significant percentage of contemporary preaching has lost its Biblical integrity because (a) it does not understand the basic need for and character of meditation, (b) it has lost the art of reading the text, (c) it does not utilize the text as source of creative structuring, and (d) it fails to understand the very nature of the text as Biblical text. Albeit an introduction, it tries to combine the contributions of the communication and literary sciences with classical homiletical approaches, for example those of Augustine and Luther, in answering the question: when can preaching be called Scriptural?

\section{INLEIDING}

'n Enkele komma uit die Bybel. Dis soms al wat nodig is om 'n mens se lewe - en die gang van die kerkgeskiedenis - in 'n nuwe rigting te stuur. Soos in die geval van Herman Kohlbrügge. Dis bekend dat hy 'n soort "tweede bekering" ondergaan het met 'n ontdekking wat hy in Romeine 7:14 gemaak het, waar die plasing van die komma ${ }^{2}$ hom tot die insig gebring het dat ook die wedergebore mens niks het om op te roem nie; en dat ook die heiligmaking ' $n$ gawe van God is. Hy skryf dat dié komma hom "dronk van troos" gemaak het, en ook: "Ek weet nie of iets in

1 Uitbreiding van 'n referaat gelewer by 'n Buvton-byeenkoms oor Liturgie en Prediking: Stellenbosch 13 Augustus 2001.

2 Die komma staan in die Griekse teks wat Kohlbrügge geraadpleeg het, nà die woord "vleeslik". In die NAV lui die teks: Ons weet tog die wet is Geestelik, maar ek is aards (OAV: vleeslik) en soos 'n slaaf aan die sonde verkoop. Hierdie doodsberig ("ek is vleeslik") was juis vir Kohlbrügge die goeie nuus van die evangelie, veral ook vir die (reeds) wedergebore mens. Omdat ek vleeslik en aan die sonde verkoop is, kan net God my in Christus heiligmaak. Hierdie beklemtoning van die objektiewe heilsfeite in Christus, tref ' $\mathrm{n}$ mens dwarsdeur die teologie van Kohlbrügge aan (vgl De Jong 1972:323; ook Aalders 1976: 79ev). 
my lewe my al meer aangegryp het as toe ek hierdie komma gesien het nie". Dié insig (wat op die 29ste Julie 1833 by hom begin wakker word het) loop uit op 'n merkwaardige preek, gelewer op 31 Julie 1833 in Wuppertal (vgl Hesse 1935:151).

Wie dronk van die troos is, kan nie anders as om daaroor te preek nie. Maar dan moet jy eers diep teue van die nuwe wyn van die teks drink. Jy moet let op elke beweging, elke intonasie, elke punktuasie van die teks. Jy moet die "Woord teen die lig" hou, soos die titel van die bekende preekreeks lui, totdat die Gees die wesenlike daarvan aan jou deursigtig maak. Dis 'n vaste vertrekpunt vir die prediking, en ook vir hierdie artikel: wie nie met die teks werk nie, het niks om in die prediking te sê nie. Of, in die woorde van Karl Barth (1964:89): "There is, therefore, nothing to be said which is not already te be found in the Scriptures".

\section{DIE STEM VAN DIE TEKS}

\section{1 'n "Ongepreekte Bybel”?}

Bogenoemde vertrekpunt kan ook andersom gesê word: as die stem van die teks nie in die prediking gehoor word nie, ís dit geen prediking nie: "Sermons not informed and inspired by Scripture are objects dislodged, orphans in the world, without mother or father" (Craddock 1985:27).

Dit is 'n goeie vraag hoeveel preke daar nie in werklikheid gepreek en gehoor word wat weeskinders-sonder-teks is nie. Trouens, daar sou 'n saak daarvoor uitgemaak kon word dat 'n ontstellende persentasie van die huidige prediking in Suid-Afrika (in elk geval wat betref die prediking oor die radio, vgl Cilliers 1996:11) as tekslose preke getipeer sou kon word. Die vraag is natuurlik: Wat presies ís Skrifprediking? Wat behels prediking wat "getrou is aan die Skrif"? Wat is die kenmerke daarvan? Hieroor is daar dikwels uiteenlopende menings. Dis die moeite werd om na die opmerkings van Karl Barth in dié verband te luister. Hy onderskei vyf kenmerke van predikers wat hulle preke in die Skrif wil veranker. Aangepas en verkort klink dit so:

- Eerstens, om jou vertroue in die Skrif te stel, dit wil sê om oortuig te wees dat die Skrif genoeg het om te bied, en dat jy nêrens elders hoef te gaan soek na antwoorde vir ons lewensvrae nie. Indien jy telkens allerlei "praktiese instruksies" wil byvoeg, is jou vertroue in die Skrif onvolkome.

- Tweedens, om die Skrif te respekteer, in die sin dat jy dit met die afwagting lees dat hierin inderdaad antwoorde vir ons lewensvrae lê. Om die Skrif só te lees, is om soos 'n mens te wees wat stadig, skynbaar moeilik lees, wat die woorde prewe- 
lend uitspel, wat die ene oë is, wat verwonderd staan oor die ontdekkings wat jy maak.

- Derdens, om die Skrif met gekonsentreerde en nougesette aandag te lees, om by die betekenis daarvan uit te kom. Hierdie nougesette lees sluit in die eksegetiese, historiese en linguistiese arbeid aan die teks, maar ook die soeke na die teologie daarin, na die nukleus van genade, na "God's message for society".

- Vierdens, om jou eie vooropgesette idees telkens weer deur die teks te laat korrigeer. Want hierdie neiging sit in ons bloed: om ons geliefkoosde teologiese konstruksies, of ons ideologieë subtiel of blatant op elke teks af te sjabloneer. Dan moet elke teks my siening van evangelisasie of sending of politieke geregtigheid buikspreek - tot vervelens toe.

- Vyfdens, om jouself voortdurend te laat meevoer deur die beweging van God se Woord. Die Bybel is nie bloot vir kognitiewe kennisname bedoel nie, maar nooi uit tot 'n ervaring van inspirasie deur die Gees. Ons het inderdaad nie bloot die teks as dooie letter nie; die Gees werk daardeur, waai daardeur - sodat ons telkens mag vra: Wat gaan die lewende God deur hierdie teks vir my sê (Barth 1964:89-92)?

Waarskynlik sou ons tussen verskillende vlakke van Skrifgeorïenteerdheid of Skrifgefundeerdheid moet onderskei. Daar is byvoorbeeld preke wat baie teksverse (dikwels op die klank af) kan aanhaal, maar dit nie noodwendig in die verkondiging ontsluit nie. Daar is preke wat die Bybelse teks in ' $n$ afgeleide sin hanteer, dit wil sê die teks nie letterlik aanhaal nie, maar tog deurdronge is van die gedagte-inhoude daarvan. In hierdie preke is die teks dan nie meer as sodanig herkenbaar nie, maar ons sou tog kon sê dat die "boodskap" nog daar is, en dat die naelstring tussen teks en preek nog nie geknip is nie. Daar is preke wat sterk eksegeties met 'n teks kan werk, maar nie daarin slaag om die brug na die konteks van die gemeente te kruis, oftewel die teks verstaanbaar as evangelie vir die tyd te vertaal nie. Daar is preke wat "expository preaching" genoem sou kon word, waarin daar 'n vers-vir-vers uitleg van 'n sekere segment van die Skrif plaasvind, sonder dat daar doelbewus gesoek word na "toepassings", of waarin die toepassings uiteindelik as 'n soort haastige addendum ná die uitleg bygevoeg word. Netso is daar preke wat wil voorgee om die teks as basis te gebruik, maar ten diepste funksioneer die teks hoegenaamd nié in die preke nie, en is die Bybelse teks in werklikheid opsioneel en uitruilbaar - blote dekor vir een of ander geestelike "boodskap". Sulke preke mag wel "Christelik" in 'n teoretiese sin van die woord genoem word, maar dit mis die spesifieke 
aanslag en unieke smaak van 'n bepaalde teks. Dat "Skrifgetroue prediking" 'n komplekse aangeleentheid is, is sondermeer duidelik. Dat die teks tóg wel op bepaalde momente deur al die blokkasies heen breek, en dat die teks by wyse van spreke wraak neem op en in ons onbeholpenheid, is niks minder as 'n Godswonder nie.

Dis in elk geval duidelik: Daar is min dinge wat predikers se prediking so kleur - en verkleur! - as hulle Skrifbeskouing. As 'n minimum moet mens aanvaar dat die teks 'n stem hét, asook iets het om te sê. Jy moet glo dat die Bybelteks nie uitgeput raak en verflou namate dit gebruik word of die historiese afstand tussen teks en leser groter word nie. God gebruik steeds die Skrif wanneer Hy sy kerk deur sy Gees en Woord van die begin van die wêreld af tot aan die einde toe vergader, beskerm en onderhou (Heidelbergse Kategismus 21/54). Die Bybel is immers nie bloot Woord van God in sy eerste gegewene nie, maar ook in elke repetisie daarvan. Dit word nie op een of ander wyse verswak deur repetisie om so minder en minder God se Woord te wees nie (Calvyn). Dit het (altyd) 'n vlymskerp stem, skerper as enige swaard met twee snykante, wat deurdring selfs tot die skeiding van siel en gees en van gewrigte en murg (Heb 4:12). Dis die oorkonde van ons verlossing, en bied die moederspraak vir die prediking van die verlossing, en die lewe uit verlossing. Wie by dié moeder gevoed word, kan nie weeskinders op die preekstoel baar nie.

Dit wil voorkom asof die prediking inderdaad al hoe meer gevaar loop om nie meer Skrifprediking te wees nie. Daar is groot dele van die Bybel waarvan die stem moit nie, of selde gehoor word. Die Bybel blyk tot 'n groot mate 'n "ungepredigte Bibel" te wees (Bohren 1996:92-94; 1971:110 ev). Die dik stroom van moralisme wat steeds deur die prediking in Suid-Afrika loop, is onder andere 'n simptoom van die feit dat predikers die teks te gou verlaat, of dalk nog nooit werklik besoek het nie (vgl Cilliers 1996:13,24). Dis byna 'n vaste reël: wie die teks verlaat, soek meestal na vinnige en werkbare skemas; hulle volg die weg van die minste weerstand, en skiet so die prediking van die teks, - die evangelie van die teks - in die voet.

Ons word geroep om in die prediking "hard aan die teks te bly"; om in ons preekoorhaastigheid verlangsaam te word - op weg na, en op pad vanaf die teks;. om met die teks te verwyl, daarmee en daarin te kuier, totdat dit vir jou soos jou eie huis begin voel; om só met die teks om te gaan, dat dit op weg saam met jou gaan, by jou bly "linger", nie as 'n platgestrykte cliché nie, maar as die vreemde, subversiewe Woord van God; dat dit in jou bly rondwoel, lank nadat jy die Bybel toegemaak het (vgl Brueggemann 1989:7-11). Ons word geroep om die teks te besoek en te herbesoek, te kou en te proe, ook te herkou en te herproe. Wie nie tyd met die teks wil deurbring nie, dit dag en nag oordink nie (Ps 1:2), 
behoort ook nie ander se tyd op - en onder - die kansel in beslag te neem nie.

Om tyd met die teks deur te bring, om dit te herkou, was byvoorbeeld vir Luther 'n saak van lewensbelang. Bohren het inderdaad aangrypend oor hierdie hele proses by Luther geskryf. Hy sluit aan by die Bybelse metafoor van eet en die Woord inneem (vgl bv Amos 8:11; Ps 19:11; Openb 10:10; Bohren 1986:75ev), en noem die herkouingsproses die wese van ware meditasie. Meditasie is die lees en weer-lees van die Skrif. Dit is om die Woord in die hart te herkou (meditari proprie est ruminare in corde). So word die hart as't ware die maag van die mensegees.

In hierdie daad van meditasie word beide die intellek en die emosie saamgevoeg om die Woord te verstaan en te verteer. Herkouing is nie bloot 'n kognitiewe aangeleentheid nie, maar ook 'n inneem van die Woord met gevoel (cum affecto). In die herhaling en herkouing van die Woord word die gevoel vir God verwek. Vir Luther is hierdie proses uiteraard ook Christologies bepaald: die ganse lewe en lyding van Jesus moet dag en nag stuksgewys in die hart opgeneem en herkou word soos ' $n$ sakramentele handeling - sodat die hart verwarm kan word, en krag en voeding (soetigheid) die mens ingegee kan word. Meditasie is dus 'n muntstuk met twee kante: ons kom in die teks in, en die teks kom in ons in.

Luther kon homself hieroor heel prakties uitdruk: dis nuttig om elke aand 'n teks in die nag saam met jou te neem, om dit in jou hart te herkou, sodat jy dit in die môre as nalatenskap van die aand weer in ontvangs kan neem, en in die lig van 'n nuwe dag se vars genade kan proe. Soms is dit nodig om 'n hele psalm, of 'n enkele psalmvers, vir 'n dag of 'n week lank te oordink en te herkou, totdat dit in jou weefsel opgeneem is en deel van jou bestaan geword het. Kortom, wie die Woord nie eet nie, kan ander ook nie daarmee voed nie (vgl Meuser 1983:88).

Die spiritualiteit van die prediker blyk dus nie net uit gebed in die algemeen nie, maar veral uit die wyse waarop gebed in verband gebring word met die omgang met die Skrif. Wie die Bybelteks vryblywend wil lees, of bloot as 'n oefening om (preek) informasie te verkry, verstaan nie wat meditasie is nie. Wie die teks wil lees, moet kom soos vir 'n piekniek, vir die aansit by 'n ete, met die verwagting om versadig te word. Of: wie die teks wil lees, moet oop wees vir die "emosie" daarin, die bui ("mood"; vgl verder punt 2.3) - en dit het niks met sentimentaliteit te make nie. Wie die teks wil lees, moet gereed wees om trane daaroor te stort, om te kla saam met die litanie daarin, maar moet ook gereed wees om daarmee saam te dans, in ritme met die melodie daarvan. Wie die teks wil lees, moet in elk geval weet: in hierdie teks sterf en leef ek. Die vraag is egter : hoe lees predikers die Bybel? 


\subsection{Hoe lees predikers die Bybel?}

Gereformeerdes bely: sola scriptura, en daarby ook nog: tota scriptura (net die Woord, die totale Woord). Hoeveel daarvan in die praktyk van die preekmaakproses tereg kom, is 'n ander vraag. Net op 'n eerste vlak word hierdie vraag krities: hoe lees predikers die Bybel? Augustinus het die opmerking gemaak dat die voortdurende lees en herlees van die Skrif, totdat jy deurdronge is daarvan, een van die primêre roepings van predikers is (vgl Van Oort 1991:15; 1989:26). Dit vorm volgens hom 'n onmisbare voorwaarde vir die hele bediening. Hierdie lectio divina is 'n eerste, "naïewe" en daaglikse lees van die Skrif, totdat jy vertroud is met die groter lyne, die omvattender verhaal van God se handelinge met mense. Augustinus het vroeg al 'n basiese probleem raakgesien: daar is te veel predikers wat tekste wil oppik, soos hoenders mieliepitte oppik, hier en daar en los en vas, sonder 'n aanvoeling vir die werfruimte van die Groot Verhaal. Die gebruik van 'n leesrooster het wel die voordeel dat dit hierdie willekeurigheid ten minste tot 'n mate uitskakel, maar dit het ook ander nadele (vir 'n kritiese bespreking, vgl Van der Walt en Du Toit 1999:112-119).

Die gedissiplineerde lees van die Bybel is 'n homiletiese (en geloofs!) onverhandelbare. Dit kán nie vermy word nie. Jy gaan nêrens begin, as jy nie êrens begin nie. Dié naïewe lees van die Bybel gaan die eksegetiese arbeid vooraf, en moet as 't ware die bedding skep waarbinne die eksegetiese arbeid en die hele preekmaak-proses kan verloop. Volgens Bohren (1996:85) verkry die Skrif sy stem in die lees daarvan, en hierdie stem vorm weer die voorveronderstelling en doel van die teologiese arbeid. In hierdie leesproses word die krag van die Skrif om self sy weg na ons toe oop te praat, vertrou. Die Skrif het sy eie ritme, sy eie polsende energie. Om 'n moderne beeld te gebruik: teksverse is soos golwe wat breek, en lesers en predikers moet leer om soos goeie branderplankryers in die momentum daarvan te kom, om die kruin te ry. Dat dít nie so 'n maklike kuns is nie, sal nie net ervare branderplankryers, oftewel predikers, kan vertel. Dikwels is meer as een onderdompeling nodig voordat jy jou voete op die branderplank, naamlik die kansel, vind!

Die uitgangspunt is: die Skrif het sy eie werking en helderheid, nie net in die private lees daarvan nie, maar ook wanneer dit in die erediens voorgelees word. Laasgenoemde is volgens Augustinus alreeds verkondiging van die heil, sonder dat enige preekkommentaar daarby hoef te kom. Dit mag na 'n vanselfsprekendheid klink, en tog bly hierdie vraag prinsipieël: hoe lees predikers die Bybel - indien wel? D L Moody se opmerking aan lidmate kan dalk ook predikers hulle leesgewoontes in heroorweging laat neem: Lees jou Bybel aan stukke...

Die feit is: jy kan nie preek as jy nie kan léés nie. Jy kan ook nie preek as jy nie kan lúister nie. In hierdie lees-en-luister-proses word al 
jou sinne opgevorder - oë, ore, gevoel, reuk, smaak, hart, verstand en verbeelding (Bugg 1992:68-76). Wie werklik lees, word in 'n nuwe wêreld ingebring, 'n wêreld waarin jy met verskerpte sinne waarneem; waarin jy proe dat die Here goed is (1 Petr 2:3). Die lees van die teks is die poort na die alternatiewe wêrelde van die teks, en so na die evangelie self.

\subsection{Die genre van die teks: bron vir kreatiewe prediking}

Die vraag na die funksionering van die teks in die preekmaak-proses is egter op ' $n$ tweede vlak krities. Normaalweg is predikers op soek na die "boodskap" van die teks vir die prediking. Dis goed so. Solank ons net verstaan dat jy nie die boodskap of inhoud van die vorm van die teks kan abstraheer nie. Eugene Peterson (1995:117) praat van 'n "contemplative exegesis" en beskryf dit só: "Contemplative exegesis means listening to the word as sound, the word that reveals out of one's interior; it also means receiving the words in the form in which they were given. For the way in which words are spoken is as important as what the words say". Eintlik kan jy nie oor 'n "tema" vanuit 'n teks preek nie. Die teks is nie soos 'n lemoen wat jy uitsuig om die sap (inhoud) te kry, om dan die skil (vorm) weg te gooi nie. Nee, die vorm is 'n aanbod; as geboekstaafde, kreatiewe vormgewing is dit dié bron vir kreatiewe vormgewing in die prediking.

Die histories-kritiese navorsing en die literatuurwetenskap is hier van waarde: dit help ons om die verrassende wendinge, die nuanses en bewegings van die teks beter in die oog te kry en vir die prediking te benut. Alhoewel hierdie wetenskappe nooit die verantwoordelikheid om oor die teks te mediteer, mag verdring nie ( $v g l 2.1)$, kan die prediker tog ook nie met behoud van 'n goeie gewete daarsónder nie. Dit beteken nie dat elke metode wat daar is, onder die knie gekry moet word, of dat alle hipoteses goedsmoeds aanvaar moet word nie, maar wel dat hierin 'n potensiaal gegee is wat krities ontgin kan word (Bohren 1971:77 ev).

Dit alles bevestig maar net weer dat ons in die prediking nie genoeg erns met die Bybelse teks kan maak nie. Die boodskap van hoop is immers daarbinne ingebed, en bly roep om ontdekking en ontginning. Die kuns van die prediking lê in die oorvertelling, die verder vertelling van dié boodskap van hoop, en dit kan op geen ander wyse gebeur as vanuit 'n konsekwente toewyding en arbeid aan die teks nie. Die teks waardeur die Gees werk - is in 'n sin ál wat ons het. Maar dis genoeg.

Hierdie konsekwente toewyding aan, en luister na die teks, sou sake soos die volgende moes insluit:

- In die prediking moet gebly word in die fundamentele kode van die teks, dit wil sê binne die werkwoordelike vorm daarvan. Om een voorbeeld te noem: dit gebeur dikwels in preke dat die 
verkondiging van heilsfeite subtiel verander word in heilsmoontlikhede, dat die verledetydsvorm 'n futurum word - wat as wet deur mense vervul moet word. Van die hoorders word dan verwag om só op te tree dat heilsmoontlikhede in heilsfeite omskep word. Maar daarmee is die troos van die evangelie weg. Daarom moet ons telkens die teks fyn in die oog kry, telkens op die fynste besonderhede let, ten einde die hoop wat in sulke verrassende wendinge skuil, ten volle vir die prediking te ontgin.

- In die prediking moet gelet word op die rol van metaforiese taal as herbeskrywing van die werklikheid, in plaas van 'n blote moralistiese etisering daarvan. Hierin bied die metafore van die Skrif aan ons 'n magtige voorbeeld - dink maar net aan die aangrypende metafore wat deur die profete oor Israel uitgespreek word, en só 'n nuwe droom, 'n nuwe visioen by hulle skep. Om weer net een voorbeeld te noem: Wanneer Esegiël sy visioen van die doodsbeendere wat lewend word aan die volk oordra (Eseg 37:1-14), is dit gevul met die hoop van 'n nuwe begin, 'n egte verandering, wat deur die Gees van die Here self bewerkstellig word. Hoe soek ons nie in Suid-Afrika na sulke hoopgewende metafore nie!

- In die prediking moet aandag gegee word aan die intensionele beweging van Bybelse tekste, dit wil sê, telkens moet gevra word: waarheen wíl hierdie teks? Wat wil dit doen en bereik? Want, dit kan ons maar glo: die diepste bedoeling van Bybelste tekste is hoopgewend, dit is om mense - die volk van God - te verander, selfs al praat die teks van sonde of van God se oordeel. Uiteindelik wil die teks ons troos met die verlossing van die evangelie, al neem hierdie trooswoord verskillende gestaltes aan, en vertoon dit ' $n$ verskeidenheid van gesigte. Die kuns van die prediking is juis om die spesifieke troosbedoeling van die teks te vind, en dit so getrou, maar ook so kreatief as moontlik oor te vertel.

- In die prediking moet erns gemaak word met die sosiologiese lees van die Bybelteks, dit wil sê met sy spesifieke historiese plasing (Sitz im Leben). Bybelse tekste het nie uit die hemel geval nie. Hulle het 'n bepaalde verlede. Dit is insiggewend dat moralisme feitlik altyd oor die historisiteit van die Bybelse teks wil spring, om by een of ander geabstraheerde "geestelike waarheid" of "wet" te kom. Moralisme teer trouens op die onthistorisering en vergeesteliking van die Skrif - en die gevolglike eksemplariese hantering daarvan (Cilliers 1996:25 
ev). Wie egter nie eerlik met die verlede van die teks omgaan nie, sal ook nie die hede en die toekoms daarvan verstaan nie.

- In die prediking moet 'n verbeeldingryke antisipasie ontwikkel word met betrekking tot die "toepassingsmoontlikhede" van die teks, eerder as 'n droë, steriele toepassing. Hoopvolle predikers is kreatiewe predikers, dit wil sê mense wat só in die wêreld van die teks leef, maar ook só in die wêreld van mense leef, dat hulle nuwe verbindings kan lê, verrassende assosiasies, wat meebring dat daar nuwe moontlikhede gesien kan word waar daar voorheen geen sigbaar was nie (Cilliers 1998:97ev). Kreatiewe predikers is mense wat ook weet dat hulle nie sonder die kreatiewe Gees kán preek nie, en daarom bly bid: Veni, Creator Spiritus, Kom, Skepper-Gees (Cilliers 2000:121-122).

Die verstaan van die wêrelde agter, van en voor die teks help ons om beter agter die kap van die byl, oftewel die swaai van die swaard van die teks te kom (oor die bydraes van Ricoeur in dié verband, vgl Vos [1996: 58-78]; ook die helder uiteensetting van Smit 1987). Hierdie navorsingsmetodes mag egter nooit as 'n doel in hulleself beskou word, of predikers só onseker ten opsigte van of sinies teenoor die teks stem dat hulle hul inspirasie vir die prediking verloor nie. Die ou wysheid van Augustinus is weer van pas: die hulpwetenskappe mag wel benut (uti) word, maar net die evangelie mag geniet (frui) word (Van Oort 1989:8)!

Om 'n enkele voorbeeld uit die oeuvre van die taalwetenskap te noem: homilete begin al hoe meer verstaan dat daar ' $n$ duidelike verband tussen die literêre genre van die teks en die prediking is. Wie sensitief vir die genre van die teks is, vra ander soort vrae aan die teks, benader dit met ' $n$ ander tipe verwagting as wat bloot in 'n kliniese soektog na die "boodskap" van die teks die geval sou wees. Die opmerkings van Long (1996:127-135) is kenmerkend van só 'n ruimer benadering:

- Laat die beweging ("movement") van die Bybelteks die beweging van die preek bepaal;

- Laat die opponerende kragte van die Bybelteks die opponerende kragte van die preek word;

- Laat die sentrale insig van die Bybelteks die sentrale insig van die preek uitmaak;

- Laat die bui ("mood") van die Bybelteks die bui van die preek kleur.

Hierdie benadering tot die Skrif verskil hemelsbreed van dié van die fundamentalisme. In laasgenoemde word onder andere die historiese en linguistiese aard van die Skrif tot 'n groot mate buite rekening gelaat, met verreikende gevolge vir die prediking. Daar is trouens min dinge wat 
kreatiewe vormgewing in die prediking so smoor soos fundamentalisme. Wie die unieke historiese en literêre aard van die teks, kan ek maar sê, die menslike aard daarvan misken, en te gou soek na "tydlose waarhede" wat op een of ander wyse in die teks verborge sou wees, verstaan na my mening nie wat sola scriptura en tota scriptura beteken nie. Die teks is vól retoriese en kommunikasiestrategieë, vól verhaalverrassings - wat wag om ook in die prediking ontgin te word. So 'n benadering is iets totaal anders as om 'n vaste skema op elke preek af te druk, sodat die gemeente later klaar weet wat volgende kom ("ek weet al wat die dominee gaan sê voordat hy/sy dit sê"). Trouens, sommige predikers saboteer eksplisiet die verrassings van die teks en die preek: hulle sê vir die gemeente wat hulle gaan doen ( 3 punte!), dan doen hulle dit, en dan sê hulle samevattend (of hulle herhaal dit in die gebed) wat hulle gesê het hulle sal doen en toe gedoen het. Geen wonder dat preek en verveling vir baie mense sinonieme geword het nie.

Die verveeldheid moet ophou, trouens, as daar één intoleransie is wat christelik is, dan is dit die een teen verveling (Bohren 1971:404). Om Bybelse tekste te lees en daaroor te preek, is opwindend; dit is ' $\mathrm{n}$ ontdekkingstog en is ontdekkingsvreugde (Barth). Dis musiek vir die ore. Volgens Mike Graves is preekmaak letterlik om soos 'n komponis én 'n dirigent te wees! Die uitdaging is om nie bloot informasie of ' $n$ morele les uit 'n Skrifgedeelte oor te dra nie, maar eerder: "to communicate the experience of a passage. This kind of preaching, like a touching piece of music, comes through the gut more than through the mind" (Graves 1997:10). Hiervoor moet die prediker volgens hom die genre van die teks verdiskonteer. Daar moet fyn geluister word na die teks, na die "mood" en die "movement" daarvan (Buttrick 1987). Die "mood" is die emosie ("state of mind or feelings") wat die teks by ons oproep, en die "movement" is die progressie, struktuur-patroon en gedagte-verdeling van die teks (Graves 1997:12). Soos 'n komponis moet die prediker na die beste musiek soek om die teks uit te voer. As dirigent moet die prediker dit dan met die mees geskikte instrumente op die planke bring. Die prediker moet as komponis-dirigent na woorde en beelde soek wat die woorde en beelde van die Skrif tot hulle reg laat kom, altans volgens die interpretasie van die prediker. Die prediker kies ' $n$ bepaalde toonsetting: kies dinamika in woorde en stemgebruik (Graves 1999:18 ev).

\subsection{Bybelste tekste: vensters op die gesig van God}

Die tegniek van die komponis-dirigent mag nooit ' $n$ doel in sigself word nie! Bybelse tekste is ook nie net retories aangrypend of literêr mooi ter wille van die kunssinnigheid daarvan nie. Bybelste tekste vertel die verhaal van God, en is as sodanig op sy openbaring gerig. Die punt is: op 
jou ontdekkingstog deur die wêreld van die teks, in die tekstuur en weefsel (texere) daarvan, loop jy 'n kans om die lewende stem van die evangelie, die viva vox evangelii te hoor. In die beddinge van die teks kan die voetspore van die Gees, oftewel die voetspore van God, gevind en gevolg word. Elke teks open nuwe wêrelde, verrassende moontlikhede, ongekende beloftes, naamlik dié van die evangelie. Bybelse tekste is in-lokkend. Dit spel die evangelie uit, nooi ons in na ' $n$ wêreld waarin ons kan sien hoe God werk. As evangelie spel dit tegelykertyd die bevryding uit tot 'n nuwe lewenswyse. In bekender terme gesê: die teks verkondig die indikatief as imperatief, en die imperatief as indikatief. En die geheim van die prediking is om dít te ontdek en hierdie ontdekking met die gemeente te deel (Cilliers 2000:21-33).

Grondliggend vir die prediking is dus die vraag: wat ís 'n (Bybel)teks? Ons sou kon sê: elke teks is 'n venster, wat 'n unieke visie op die gesig van God oopmaak. Meer nog: elke teks is 'n veelheid van vensters, is 'n kaleidoskoop van insigte en van nuwe perspektiewe op die gesig van God. Tekste bevat as sodanig meer as een waarheid oor God; meer as een interpretasie is daarom nie net moontlik nie, maar gewens. Wie 'n teks lees met die oog op die distillering van 'n enkele, "ewige waarheid" daaruit, loop gevaar om die teks te versmal en uiteindelik te bederf. Wie tevrede is om één diamant op die delwerssif van die eksegetiese arbeid te ontdek, het nog nie diep genoeg in die myn van die teks gedelf nie. Of, wie net bly staar na één kant van die diamant, en dit nie telkens in die prediking in die rondte draai nie, sal nooit die volle vonkeling daarvan ervaar nie. Jy kan die skat in jou hand hou, sonder om die rykdom daarvan te verstaan. Net so kan 'n goeie teks blykbaar in die hande van slegte mense 'n slegte teks word, en 'n slegte teks in die hande van goeie mense 'n goeie teks (Rabbi Tzvi Marx). ${ }^{3}$

Die roeping van predikers is om in die prediking telkens ' $n$ nuwe kant van God se gesig, 'n nuwe perspektief op sy genadige teenwoordigheid aan die gemeente, te bemiddel. Dít kan egter nie gedoen word sonder dat daar deur die bril van die Skrif gekyk word nie. Dis alleen wanneer die lens van die Skrif, die spesifieke lens van 'n spesifieke teks ons oë fokus op 'n spesifieke openbaring van God, dat predikers ander kan uitnooi om saam met mekaar deur dié lens te kyk. Trouens, die sin van die prediking is juis om as gemeente deur die teks heen 'n nuwe perspektief op God te verkry, en daarom ook op onsself en die wêreld waarin ons ons bevind.

Hierdie perspektief is presies dit: 'n perspektief, 'n hoek van visie, 'n waarneming vanuit die plek waar jy staan. Dit kan dus nie ánders as

3 In 'n ongepubliseerde referaat, gelewer by die konferensie van die Societas Homiletica in Doorn, Nederland (16-21 Junie 2001). 
om kontekstueel te wees nie. Dit kan ook nie anders as om eksperimenteel te wees nie, in dié sin dat jy voortdurend weet dat daar ook ánder perspektiewe en ánder interpretasies van hierdie openbaring van God moontlik is. Daarom is elke perspektief, elke preek ook beperk. Dit moet ook nie voorgee om die volle prentjie van die volle waarheid aan die gemeente voor te hou nie. Preke is stukwerk, is fragmente, en as sodanig oop uitnodigings dat ander ook met vrymoedigheid húlle perspektiewe deur die lens van die teks mag verwoord. Preke staan onder 'n eskatologiese voorbehoud: "Want ons ken maar gedeeltelik, en ons verkondig God se wil maar gedeeltelik, maar wanneer die volledige kom, sal wat gedeeltelik is, uitgedien wees" (1 Kor. 13:9, 10).

Maar die wonder bly: God openbáár sy gesig deur die teks. Sy Woord wérk. Is daar 'n biografie wat dít beter illustreer as dié van Augustinus ${ }^{4}$ ?

God het gepráát deur die lewende stem van die teks.

Genoeg om dronk van troos te raak.

\section{Literatuurverwysings}

Aalders, W 1976. Herman Friedrich Kohlbrügge. Zijn leven, zijn prediking, zijn geschriften. Den Haag: J N Voorhoeve.

Augustinus, S, 1938. The confessions of $S$ Augustine, Revised by Rev E B Pusey, John Henry Parker; J G and F Rivington: London.

Barth, K 1964. Prayer and preaching. London: SCM.

-, 1971. Predigtlehre. München: Kaiser

-, 1986. Lebenstil. Fasten und Feiern. Neukirchen-Vluyn: Neukirchener Verlag.

4 Ek het myself onder 'n vyeboom neergegooi en my trane vrylik laat vloei. Ek het jammerlik na bo geroep: Hoe lank, hoe lank? Môre en môre? Hoekom nie nou nie? Hoekom kom daar nie in hierdie uur' $n$ einde aan my onreinheid nie?

Ek was besig om hierdie dinge te sê en te huil in gebrokenheid van hart, en skielik het ek die stem van 'n seun of 'n dogter gehoor - ek weet nie watter een nie - wat van 'n naburige huis gekom het, en singend 'n paar keer herhaal het: Tolle, lege! Tolle, lege! (Neem, lees! Neem, lees!)

Ek het onmiddellik opgehou om te huil, en ek het gewonder of dit dalk moontlik sou kon wees dat kinders sulke woorde in enige soort speletjie sou gebruik, want ek kon nie onthou dat ek so iets al ooit tevore gehoor het nie. Ek het opgestaan, want ek kon aan niks anders dink nie as dat hierdie 'n Goddelike opdrag aan my was om die Bybel oop te maak en die eerste gedeelte te lees waarop my oë sou val.

Ek het vinnig teruggekeer na die bank waar Alypius gesit het, want dis waar ek die apostel Paulus se brief aan die Romeine laat lê het. Ek het dit opgeraap, oopgemaak, en in stilte die gedeelte gelees waarop my oë eerste geval het: Nee, julle moet lewe soos volgelinge van die Here Jesus Christus en nie voortdurend daarop uit wees om julle sondige begeertes te bevredig nie (Rom. 13:14).

Ek wou niks verder lees nie, dit was ook nie nodig nie, want onmiddellik, soos wat die sin geëindig het, het daar iets soos die lig van volle sekerheid in my hart ingeskyn, en al die duisternis van twyfel het verdwyn". 
-, 1996. Praktische Theologie als Wissenschaftskritik. Anmerkungen zu Günter Grass: "Über das Sekundäre aus primärer Sicht", in: Predigen aus Leidenschaft. Karlsruhe: Verlag Evangelischer Presseverband für Baden e. V.

Bohren, R 1971. Predigtlehre. Munchen: Kaiser.

Bohren, R 1986. Lebenstil. Fasten und Feiern. Neukirchen-Vluyn: Neukirchener Verlag.

-, 1996. Praktische Theologie als Wissenschaft. Anmerkungen zu Gunter Grass: "Uber das Sekundare aus primarer Sicht", in: Predigen aus Leidenschaft. Karlsruhe: Verlag Evangelischer Presseverband fur Baden e.V.

Brueggemann, W 1989. Finally comes the poet. Daring speech for proclamation. Minneapolis: Fortress.

Bugg, C B 1992. Preaching from the inside out. Nashville, Tennessee: Broadman.

Buttrick, D 1987. Homiletic: Moves and structures. Philadelphia: Fortress.

Cilliers, J 1996. Die uitwissing van God op die kansel. Onstellende bevindinge oor Suid-Afrikaanse prediking. Kaapstad: Lux Verbi.

-, 1998. Die uitwysing van God op die kansel. hspirerende perspektiewe op die prediking - om God te sien en ander te lààt sien. Kaapstad: Lux Verbi.

-, 2000. Die genade van gehoorsaamheid. Hoe evangelies is die etiese preke wat ons in Suid-Afrika hoor? Kaapstad: Lux Verbi.

Craddock, F 1985. Preaching. Nashville: Abingdon.

De Jong, O J 1972. Nederlandse Kerkgeschiedenis. Nijkerk: Callenbach.

Graves, M 1997. The Sermon as Symphony. Preaching the literary forms of the New Testament. Pasadena: Judson.

Hesse, H K 1935. Herman Friedrich Kohlbrügge. Wuppertal-Barmen: Emil Müllers Verlag.

Long, T G 1996. Preaching and the literary forms of the Bible. Philadelphia: Fortress.

Meuser F W 1983. Luther the preacher. Minneapolis: Augsburg.

Peterson, E H 1995. Working the angles. The shape of pastoral integrity. Michigan: Eerdmans.

Smit, D J 1987. Hoe verstaan ons wat ons lees? 'n Dink - en werkboek oor die hermeneutiek vir predikers en studente. Kaapstad: NG Kerk-Uitgewers.

Van der Walt, P J \& Du Toit, C 1999: Vrae oor die "revised common lectionary" as hulpmiddel vir die bediening van die Woord in gemeentes. PTSA 14/2: 112119.

Van Oort, J 1989. Augustinus. Facetten van leven en werk. Kampen: Kok.

-, 1991. Bediening van het heil. Augustinus over de prediking. Leiden: Uitgeverij J J Groen en Zoon.

Vos, C J A 1996. Homiletiese flitse in die hermeneutiese spieël van Paul Ricoeur, 1 \& 2. PTSA 11/1: 58-78. 